\title{
Treatment of synchronous adenocarcinoma and lymphoma of the stomach: A case report
}

\author{
CHIEN-HSIANG WENG ${ }^{1-3}$, REN-CHING WANG $^{4}$, CHENG-CHUNG WU ${ }^{5}$ and TSENG-HSI LIN ${ }^{3,6,7}$ \\ ${ }^{1}$ NH Dartmouth Family Medicine Residency, Concord Hospital, Concord, NH 03301; ${ }^{2}$ Bloomberg School of Public Health, \\ Johns Hopkins University, Baltimore, MD 21205, USA; ${ }^{3}$ Division of Hematology/Oncology, Department of Internal \\ Medicine; ${ }^{4}$ Department of Pathology and Laboratory Medicine; ${ }^{5}$ Division of General Surgery, Department of Surgery; \\ ${ }^{6}$ Division of Transfusion Medicine, Department of Pathology and Laboratory Medicine, Taichung Veterans General Hospital, \\ Taichung 40705; ${ }^{7}$ Department of Medicine, Chung Shan Medical University, Taichung 40201, Taiwan, R.O.C.
}

Received June 3, 2016; Accepted August 18, 2016

DOI: $10.3892 / \operatorname{mco} .2016 .1044$

\begin{abstract}
Gastric cancer is one of the leading causes of cancer-related mortality worldwide. The majority of gastric cancers are diagnosed at an advanced or metastatic stage, with a 5-year survival rate of $\sim 5-20 \%$ and a median overall survival of $<1$ year. Synchronous occurrence of gastric adenocarcinoma and lymphoma is rare, and thus far there is no consensus regarding their management. We herein describe a case of synchronous gastric adenocarcinoma and diffuse large B-cell lymphoma in a patient with chronic hepatitis B and the treatment strategy. A literature review with the most up-to-date treatment options and their application in similar situations was also performed.
\end{abstract}

\section{Introduction}

Gastric cancer is the second most common cause of cancer-related mortality and the fourth most commonly diagnosed type of cancer worldwide $(1,2)$. The majority of gastric cancers are diagnosed at an advanced or metastatic stage, with a 5-year survival rate of 5-20\% and a median overall survival of $<1$ year (1). In countries with a high gastric cancer prevalence, such as Japan, early screening programs help to detect early-stage gastric cancer, which has a 5-year survival rate of $90 \%$. The three most common types of gastric malignancies are gastric adenocarcinoma, gastrointestinal stromal tumor and primary gastric lymphoma. The occurrence of synchronous gastric adenocarcinoma and lymphoma is rare, and there is currently no consensus regarding their management. Thus,

Correspondence to: Dr Tseng-Hsi Lin, Division of Transfusion Medicine, Department of Pathology and Laboratory Medicine, Taichung Veterans General Hospital, 160 Chung-Kang Road, Section 3, Taichung 40705, Taiwan, R.O.C.

E-mail: jth.lin@gmail.com

Key words: gastric adenocarcinoma, diffuse large B-cell lymphoma, hepatitis B decision-making regarding the optimal treatment strategy may be challenging.

We herein describe the case of a patient who was diagnosed with synchronous gastric adenocarcinoma and gastric diffuse large B-cell lymphoma. Prioritizing treatment in such patients is crucial, and certain factors, such as Helicobacter pylori (H.pylori) infection, must be taken into consideration during the decision-making process.

\section{Case report}

A 51-year-old Chinese man was referred to the Taichung Veterans General Hospital from a community hospital with a history of general malaise, poor appetite, abdominal fullness and a weight loss of $10 \%$ over the past month. The patient was a chronic hepatitis B carrier, had a 30 pack-year smoking history (one pack per day for 30 years), and had suffered from epigastric discomfort for several years without seeking medical attention. There was no fever or night sweats. An abdominal contrast-enhanced computed tomography scan revealed multiple lymphadenopathies in the abdominal cavity, and the initial esophagogastroduodenoscopy revealed an irregularly elevated area in the lower-to-middle gastric body; the biopsies showed moderately differentiated adenocarcinoma and diffuse mixed small and large B-cell lymphoma. No H. pylori was identified on examination of Giemsa-stained specimens. As the patient refused total gastrectomy, one cycle of epirubicin, cisplatin and fluorouracil (ECF regimen) was initially administered for gastric adenocarcinoma as neoadjuvant therapy; 1 month later, a bone marrow biopsy revealed diffuse mixed small and large B-cell lymphoma negative for CD20 expression, and the patient received 8 cycles of cyclophosphamide, adriamycin, vincristine and prednisone (CHOP regimen).

Seven months later, the patient underwent distal subtotal gastrectomy and the pathological examination confirmed the diagnosis of poorly differentiated adenocarcinoma (Fig. 1) and diffuse large B-cell lymphoma (DLBCL) (Fig. 2), positive for CD20 and negative for H.pylori. Following surgery, the patient received 8 cycles of rituximab, cyclophosphamide, mitoxantrone, vincristine and prednisone (R-CNOP regimen) instead of CHOP to reduce cardiotoxicity, and achieved 


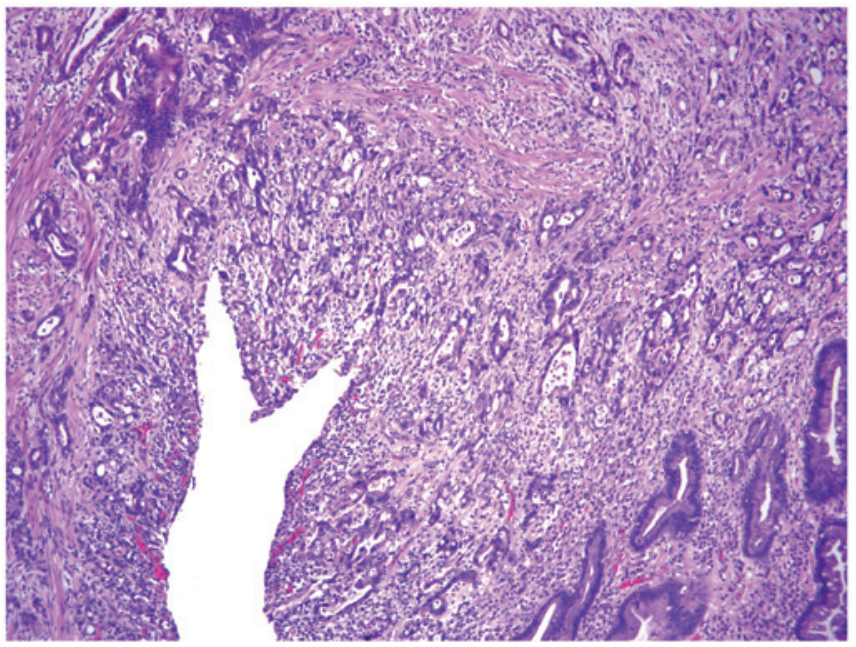

Figure 1. Gastric adenocarcinoma invading through the muscularis mucosa, with abortive glandular structure and infiltrative growth pattern. Hematoxylin and eosin staining; magnification, x100.

complete remission of the DLBCL. The patient declined further chemotherapy for the gastric adenocarcinoma due to the deterioration of his liver function.

Three years later, the patient presented with obstructive jaundice. Laparoscopic biopsy at the porta hepatis showed moderately to poorly differentiated metastatic adenocarcinoma (Fig. 3). Immunohistochemical staining revealed $2+$ human epidermal growth factor-2 (HER-2) expression. Four cycles of capecitabine plus oxaliplatin were administered and trastuzumab treatment was recommended. However, trastuzumab was not initiated due to the patient's financial difficulties. After 6 months, the patient achieved near complete remission radiographically and was followed up for another 6 months at the oncology clinic; however, he succumbed to metastatic disease after $\sim 1$ year.

\section{Discussion}

Gastric cancer is the second most common cause of cancer-related mortality worldwide (1-3). Approximately 70\% of gastric cancer cases are associated with $H$. pylori infection, and $5.5 \%$ of all cancer cases globally are $H$. pylori-associated gastric cancer $(2,4,5)$. H. pylori infection is very common in several parts of the world; its prevalence may be $\geq 50 \%$ in certain areas, particularly in developing countries (4). Among individuals infected by $H$. pylori, $\sim 1-2 \%$ may develop gastric cancer, including adenocarcinoma and mucosa-associated lymphoid tissue (MALT) lymphoma (3,6,7). Risk factors include the strain of $H$. pylori, the duration of the infection, host genetic polymorphisms, and diet or other environmental factors (8-13). In cases with synchronous adenocarcinoma and lymphoma, $H$. pylori infection was present in $92 \%$ of the cases in Eastern countries and $68 \%$ of the cases in Western countries (14), although it remains rare for synchronous tumors. Among all histological types of gastric lymphoma, DLBCL and MALT lymphoma are the types most significantly associated with $H$. pylori infection $(15,16)$. The possible mechanism underlying $H$. pylori as a causative factor for gastric lymphoma is that chronic infection with $H$. pylori causes hormonal and cellular

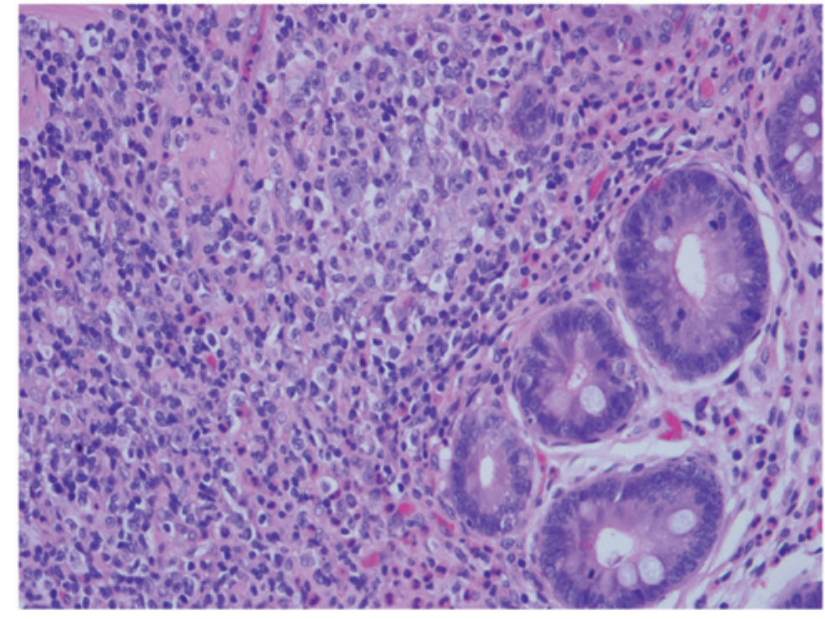

Figure 2. Large atypical lymphocytes infiltrating the lamina propria with sheet-like aggregations. Hematoxylin and eosin staining; magnification, $\mathrm{x} 400$.

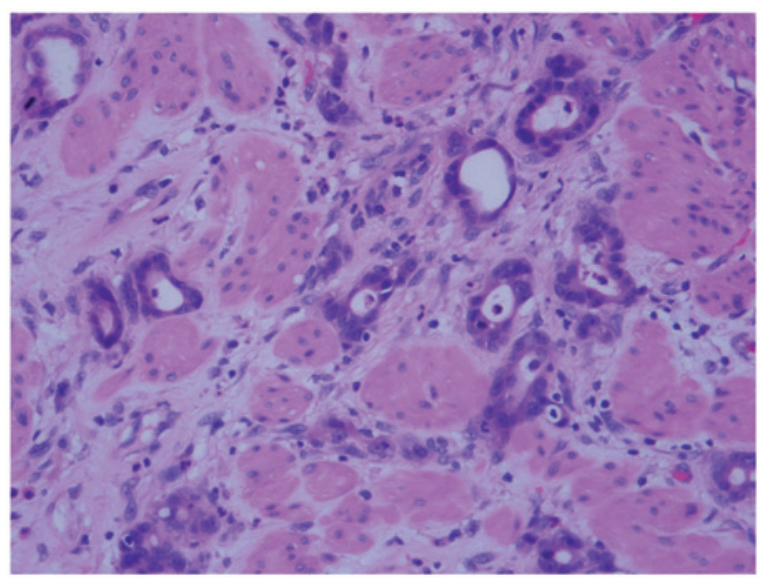

Figure 3. Abortive glandular structures invading the muscularis propria. Hematoxylin and eosin staining; magnification, $x 400$.

changes and damages the gastric cells. The damaged gastric cells then induce clonal expansion of B cells $(17,18)$. Thus, the current concept suggests $H$. pylori eradication as an effective method in treating low-grade gastric lymphoma $(18,19)$. In high-grade gastric lymphoma or DLBCL, due to a higher number of genetic mutations, the response to $H$. pylori eradication appears to be more limited $(15,20)$.

The positive correlations between Epstein-Barr virus (EBV) infection, gastric carcinoma and DLBCL have been investigated and confirmed $(21,22)$. Approximately $10 \%$ of gastric carcinomas are EBV-positive, as are $9 \%$ of DLBCLs $(21,22)$. The positivity of EBV infection in patients with DLBCL is associated with poorer response to treatment and survival (22). Chronic HBV infection may increase the risk of non-Hodgkin lymphoma (NHL) by 3 times, particularly in DLBCL $(23,24)$.

Our patient was diagnosed with synchronous gastric adenocarcinoma and diffuse large B-cell lymphoma, whereas H. pylori infection was not identified. Since the patient initially refused gastrectomy and was later found to have co-existing DLBCL with bone marrow involvement, the $\mathrm{CHOP}$ regimen was recommended prior to receiving subtotal gastrectomy, as DLBCL is an aggressive NHL and bone marrow involve- 
ment indicates a more aggressive condition with a worse outcome. Patients with chronic hepatitis B infection may have compromised liver function and may not be able to tolerate the stronger hepatotoxicity associated with standard chemotherapy for gastric adenocarcinoma. Our patient presented with metastasis of residual adenocarcinoma 3 years after the gastrectomy. Although the patient responded well to standard chemotherapy, from 2010 onwards there is another option for patients with synchronous tumors and HER-2 positivity.

Studies suggest that the use of trastuzumab in patients with HER2-positive advanced gastric or gastro-oesophageal junction cancer significantly improved overall survival, with a $26 \%$ reduction in mortality and prolongation of the median overall survival (13.8 vs. 11.1 months) (1). The addition of trastuzumab to chemotherapy does not increase the toxicity associated with standard fluoropyrimidine-based (5-fluorouracil) and platinum-based chemotherapy (1). Treatment with trastuzumab and platinum may be a suitable and effective option for patients with HER-2-positive gastric adenocarcinoma who cannot tolerate strong hepatotoxicity. In the current 2016 NCCN guidelines for gastric cancer treatment, the addition of trastuzumab to standard chemotherapy is recommended as a first-line treatment option for HER-2-positive patients (25). For cases similar to our patient, trastuzumab may be added regardless of the status of HER-2 expression, since the biopsy result may not represent the expression status in all malignant tissues and tumor cells exhibit a high mutation rate.

In conclusion, for patients diagnosed with synchronous gastric adenocarcinoma and lymphoma, a number of factors must be taken into consideration during decision-making in terms of which cancer to treat first and which is the optimal regimen. EBV and HBV play important roles in adenocarcinoma as well as lymphoma. HER-2-positive patients with poor liver function may be treated with trastuzumab in addition to platinum-based chemotherapy. Surgical resection and subsequent pathological examination of the tumor may offer more precise information regarding the tumor types and optimal treatment.

\section{Acknowledgements}

The present study was performed in Taichung Veterans General Hospital (Taichung, Taiwan, R.O.C.). The patient has signed an informed consent regarding the publication of the case details.

\section{References}

1. Bang YJ, Van Cutsem E, Feyereislova A, Chung HC, Shen L, Sawaki A, Lordick F, Ohtsu A, Omuro Y, Satoh T, et al: Trastuzumab in combination with chemotherapy versus chemotherapy alone for treatment of HER2-positive advanced gastric or gastro-oesophageal junction cancer (ToGA): A phase 3, open-label, randomised controlled trial. Lancet 376: 687-697, 2010.

2. Kim SS, Ruiz VE, Carroll JD and Moss SF: Helicobacter pylori in the pathogenesis of gastric cancer and gastric lymphoma. Cancer Lett 305: 228-238, 2011.

3. Correa P and Piazuelo MB: Helicobacter pylori infection and gastric adenocarcinoma. US Gastroenterol Hepatol Rev 7: 59-64, 2011.

4. Testerman TL and Morris J: Beyond the stomach: An updated view of Helicobacter pylori pathogenesis, diagnosis, and treatment. World J Gastroenterol 20: 12781-12808, 2014.

5. Mbulaiteye SM, Hisada M and El-Omar EM: Helicobacter pylori associated global gastric cancer burden. Front Biosci (Landmark Ed) 14: 1490-1504, 2009.
6. Herrera V and Parsonnet J: Helicobacter pylori and gastric adenocarcinoma. Clin Microbiol Infect 15: 971-976, 2009.

7. Brawner KM, Morrow CD and Smith PD: Gastric microbiome and gastric cancer. Cancer J 20: 211-216, 2014.

8. Atherton JC, Cao P, Peek RM Jr, Tummuru MK, Blaser MJ and Cover TL: Mosaicism in vacuolating cytotoxin alleles of Helicobacter pylori. Association of specific vacA types with cytotoxin production and peptic ulceration. J Biol Chem 270: 17771-17777, 1995

9. Ziel KA, Campbell CC, Wilson GL and Gillespie MN: Ref-1/Ape is critical for formation of the hypoxia-inducible transcriptional complex on the hypoxic response element of the rat pulmonary artery endothelial cell VEGF gene. FASEB J 18: 986-988, 2004.

10. Harris PR, Smythies LE, Smith PD and Perez-Perez GI: Role of childhood infection in the sequelae of $H$. pylori disease. Gut Microbes 4: 426-438, 2013.

11. Lee WP, Tai DI, Lan KH, Li AF, Hsu HC, Lin EJ, Lin YP, Sheu ML, Li CP, Chang FY, et al: The -251T allele of the interleukin-8 promoter is associated with increased risk of gastric carcinoma featuring diffuse-type histopathology in Chinese population. Clin Cancer Res 11: 6431-6441, 2005.

12. Shikata K, Kiyohara Y, Kubo M, Yonemoto K, Ninomiya T, Shirota T, Tanizaki Y, Doi Y, Tanaka K, Oishi Y, et al: A prospective study of dietary salt intake and gastric cancer incidence in a defined Japanese population: The Hisayama study. Int J Cancer 119: 196-201, 2006.

13. Correa P, Fontham ET, Bravo JC, Bravo LE, Ruiz B, Zarama G, Realpe JL, Malcom GT, Li D, Johnson WD and Mera R: Chemoprevention of gastric dysplasia: Randomized trial of antioxidant supplements and anti-Helicobacter pylori therapy. J Natl Cancer Inst 92: 1881-1888, 2000.

14. Chan AO, Chu KM, Yuen ST, Leung SY, Lam SK and Wong J: Synchronous gastric adenocarcinoma and mucosa-associated lymphoid tissue lymphoma in association with Helicobacter pylori infection: Comparing reported cases between the East and West. Am J Gastroenterol 96: 1922-1924, 2001.

15. de Sanjose S, Dickie A, Alvaro T, Romagosa V, Garcia Villanueva M, Domingo-Domenech E, Fernandez de Sevilla A and El-Omar E: Helicobacter pylori and malignant lymphoma in Spain. Cancer Epidemiol Biomarkers Prev 13: 944-948, 2004.

16. Parsonnet J, Hansen S, Rodriguez L, Gelb AB, Warnke RA, Jellum E, Orentreich N, Vogelman JH and Friedman GD: Helicobacter pylori infection and gastric lymphoma. N Engl J Med 330: 1267-1271, 1994.

17. Hussell T, Isaacson PG, Crabtree JE, Dogan A and Spencer J: Immunoglobulin specificity of low grade B cell gastrointestinal lymphoma of mucosa-associated lymphoid tissue (MALT) type. Am J Pathol 142: 285-292, 1993.

18. Wotherspoon AC, Doglioni C, Diss TC, Pan L, Moschini A, de Boni M and Isaacson PG: Regression of primary low-grade B-cell gastric lymphoma of mucosa-associated lymphoid tissue type after eradication of Helicobacter pylori. Lancet 342: 575-577, 1993.

19. Cavanna L, Pagani R, Seghini P, Zangrandi A and Paties C: High grade B-cell gastric lymphoma with complete pathologic remission after eradication of Helicobacter pylori infection: Report of a case and review of the literature. World J Surg Oncol 6: 35, 2008.

20. Liu H, Ye H, Ruskone-Fourmestraux A, De Jong D, Pileri S, Thiede C, Lavergne A, Boot H, Caletti G, Wündisch T, et al: $\mathrm{T}(11 ; 18)$ is a marker for all stage gastric MALT lymphomas that will not respond to H. pylori eradication. Gastroenterology 122 : 1286-1294, 2002.

21. Fukayama $M$ and Ushiku T: Epstein-Barr virus-associated gastric carcinoma. Pathol Res Pract 207: 529-537, 2011

22. Park S, Lee J, Ko YH, Han A, Jun HJ, Lee SC, Hwang IG, Park YH, Ahn JS, Jung CW, et al: The impact of Epstein-Barr virus status on clinical outcome in diffuse large B-cell lymphoma. Blood 110: 972-978, 2007.

23. Engels EA, Cho ER and Jee SH: Hepatitis B virus infection and risk of non-Hodgkin lymphoma in South Korea: A cohort study. Lancet Oncol 11: 827-834, 2010.

24. Ulcickas Yood M, Quesenberry CP Jr, Guo D, Caldwell C, Wells K, Shan J, Sanders L, Skovron ML, Iloeje U and Manos MM: Incidence of non-Hodgkin's lymphoma among individuals with chronic hepatitis B virus infection. Hepatology 46: 107-112, 2007.

25. NCCN: National Comprehensive Cancer Network Guidelines for gastric cancer. Version 3, 2016. https://www.nccn.org/professionals/physician_gls/f_guidelines.asp. Accessed September 12, 2016. 